\title{
Premature ageing and inflammatory status of ovariectomized mice. Treatment with soybean isoflavones and green tea
}

\author{
I. Baeza, N. M. De Castro and M. De La Fuente \\ Department of Physiology, Faculty of Biology, Complutense University of Madrid, Madrid, Spain
}

\begin{abstract}
Ageing is characterised by a mild pro-inflammatory status ${ }^{(1)}$. Ovariectomy in rodents constitutes a model of premature ageing that accelerates immunosenescence and increases oxidative stress in rodents ${ }^{(2,3)}$. Previous experiments showed that ovariectomy causes an unbalance in the pro-/anti-inflammatory cytokine levels in old mice $(20 \text { months of age })^{(4)}$. The present study focused on the dysbalance of inflammatory markers after ovariectomy, in late maturity female mice, as well as on the readjustment that takes place after the administration of soybean and green tea enriched diets. Female ICR-CD1 mice were used. They were ovariectomized or sham-operated at a mature age (13 months) in order to mimic human menopause. At 16 months of age, they were administered a diet rich in soy isoflavones $(1 \mathrm{mg} / \mathrm{mouse} / \mathrm{d})$ or a combined diet rich in soy isoflavones $(1 \mathrm{mg} / \mathrm{mouse} / \mathrm{d})$ and green tea $(3.75 \mathrm{mg} / \mathrm{mouse} / \mathrm{d})$ (Diviser-Aquilea, S.L.) for 5 weeks. Control groups received standard diet. At 17 months (late mature mice), peritoneal leucocytes were obtained and set in $72 \mathrm{~h}$ cultures in response to the mitogens ConA and LPS. IL-2 and IL-10 levels were measured in ConA supernatants and IL-6 levels were analysed in LPS supernatants. Ovariectomy decreases IL-10 levels and also tends to reduce those of IL-2, while IL-6 levels are not affected. Moreover, treatments with soybean isoflavones and green tea increase IL-2 and IL-10 levels in ovariectomized mice. The combined treatment with isoflavones and green tea is able to decrease IL-6 levels. Sham animals do not show any differences. The inflammatory condition in late maturity mice gets altered by ovariectomy through a decrease of IL-10 cytokine levels. Furthermore, such an inflammatory state is partially reversed by the ingestion of soy isoflavones during a period of 5 weeks.
\end{abstract}
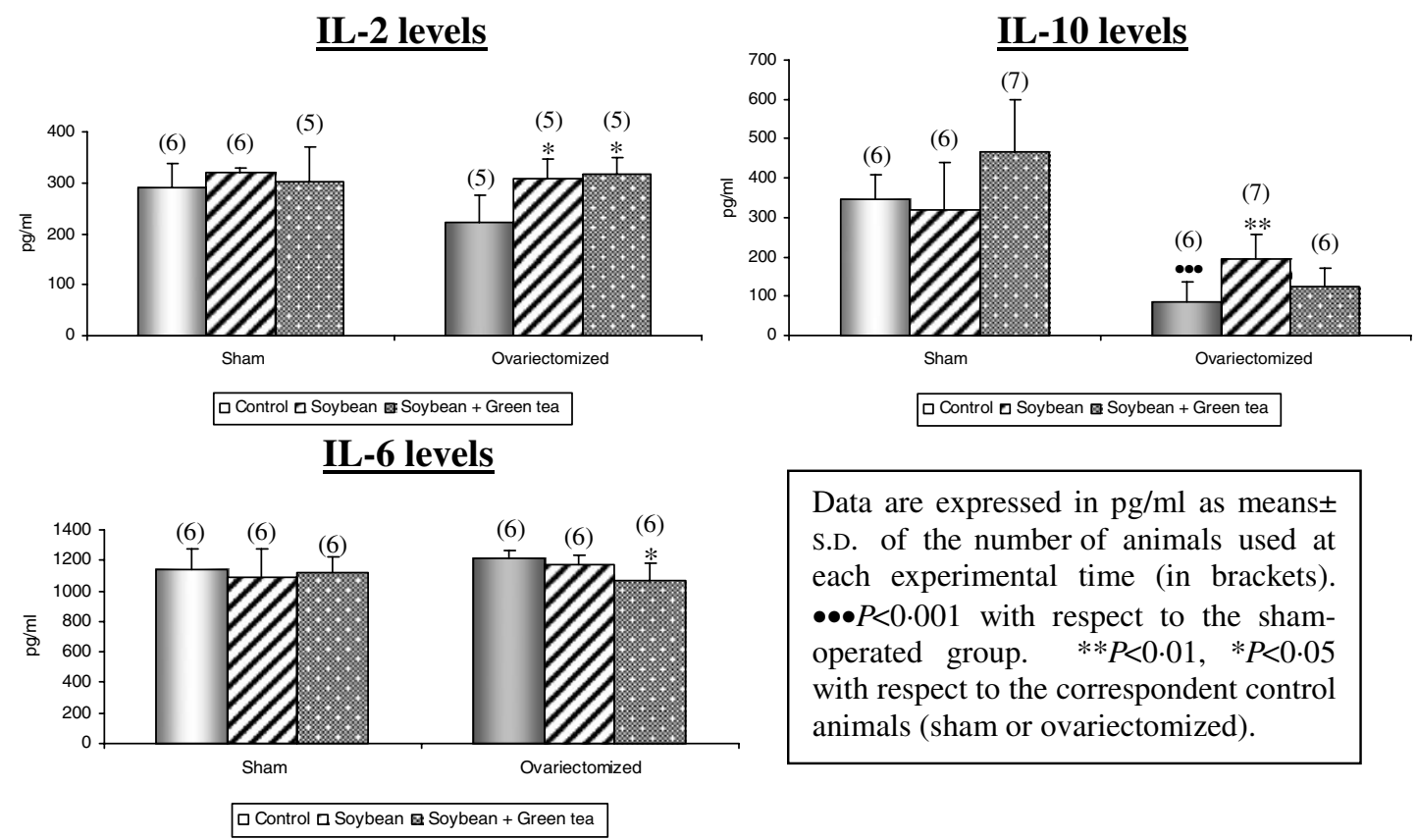

Data are expressed in $\mathrm{pg} / \mathrm{ml}$ as means \pm S.D. of the number of animals used at each experimental time (in brackets). $\bullet \bullet \bullet<0 \cdot 001$ with respect to the shamoperated group. $\quad * * P<0 \cdot 01, \quad * P<0 \cdot 05$ with respect to the correspondent control animals (sham or ovariectomized).

Financial support: BFU2005-06777, BFU2008-04336, 910379ENEROINN and RETICEF (RD06/0013/0003)

1. Franceschi C (2007) Nutr. Rev 65, S173-S176.

2. De la Fuente M, Baeza I, Guayerbas N et al. (2004) Biogerontology 5, 389-400.

3. Kankofer M, Radzki RP, Bienko M et al. (2007) J Vet Med 54, 225-229.

4. Baeza I, De Castro NM \& De la Fuente M (2009) Acta Physiol 195, 99. 